\title{
Body mass index as a prognostic factor in patients with extranodal natural killer/T-cell lymphoma, nasal type
}

\author{
Jie Liu ${ }^{1}$, Yao-Tiao Deng ${ }^{1}$, Li Zhang ${ }^{1}, \mathrm{Na} \mathrm{Li}^{1}$, Ming Jiang ${ }^{1}$, Li-Qun Zou' ${ }^{1}$ and Yu Jiang ${ }^{1}$ \\ 1 Department of Medical Oncology, Cancer Center, State Key Laboratory of Biotherapy, West China Hospital, Sichuan \\ University, Chengdu, China \\ Correspondence to: Yu Jiang, email: jiang_yu@scu.edu.cn
}

Li-qun Zou , email: zliqun@hotmail.com

Keywords: extranodal natural killer/T-cell lymphoma, body mass index, prognosis, radiotherapy, chemotherapy

Received: May 10,2016 Accepted: August 13, $2016 \quad$ Published: August 18, 2016

\section{ABSTRACT}

Epidemiological evidence has shown that body mass index (BMI) can predict survival in several types of cancer. However, the role of BMI in extranodal natural killer/T-cell lymphoma, nasal type (ENKTL) is still unclear. This retrospective singlecenter study included $\mathbf{2 5 1}$ newly diagnosed patients to determine the prognostic value of BMI in ENKTL. Of these, 203 patients received chemoradiotherapy, 37 received chemotherapy alone, 8 received radiotherapy alone, and 3 received only best supportive care. With a median follow-up of $\mathbf{2 8}$ months, the estimated 3-year overall survival (OS) and progression-free survival (PFS) rates were $64.4 \%$ and $60.9 \%$, respectively. The receiver-operating characteristic curve showed that $20.8 \mathrm{~kg} / \mathrm{m}^{2}$ was the optimal cut-off of BMI to predict survival. BMI $<20.8 \mathrm{~kg} / \mathrm{m}^{2}$ was associated with lower 3-year OS (52.8\% vs. $72.9 \%, P=0.001)$ and PFS (48.8\% vs. $69.8 \%, P$ $<0.001$ ) rates. Multivariate analysis indicated that BMI, performance status, lactate dehydrogenase (LDH) levels, chemotherapy, and radiotherapy were independent prognostic factors for OS. Furthermore, BMI, number of extranodal sites, performance status, LDH, and radiotherapy were predictive of PFS. These results suggest that BMI at the cut-off of $20.8 \mathrm{~kg} / \mathrm{m}^{2}$ might be a prognostic factor in patients with ENKTL.

\section{INTRODUCTION}

Extranodal natural killer/T-cell lymphoma, nasal type (ENKTL) is a rare subset of non-Hodgkin's lymphoma (NHL). It is more frequent in Asia and Latin America, accounting for $7 \%-10 \%$ of all NHLs in these areas, but only $1 \%$ in western countries [1]. ENKTL can be dichotomized as nasal disease primarily localized to the upper aerodigestive tract (UAT), or extranasal disease occurring in non-UAT sites (e.g., skin, intestine, testicles) [2]. According to the data from the International Peripheral T-Cell Lymphoma Project, the median overall survival (OS) was only 0.36 and 1.6 years for extranasal and nasal disease, respectively [2]. In 2006, Lee et al. established a prognostic model for ENKTL, known as the Korean Prognostic Index, which contained four factors: B symptoms, serum lactate dehydrogenase (LDH) level, stage, and regional lymph node (RLN) involvement [3]. In this study, most patients $(202 / 262)$ had received anthracycline-based chemotherapy [3]. Recently, the survival of ENKTL patients has improved owing to early radiotherapy and new chemotherapy regimens containing asparaginase and other non-anthracycline drugs [2, 4-10]. The prognostic index of natural killer lymphoma (PINK) model published in 2016 was developed for patients who received non-anthracycline-based chemotherapy with or without radiotherapy, based on their clinical characteristics including age, stage, distant lymph node (DLN) involvement, and non-nasal type disease [11].

Body mass index (BMI) is one of the common criteria to evaluate the degree of obesity. Increased BMI is associated with a higher risk of diabetes mellitus, cardiovascular diseases [12], as well as cancers [13]. Recent evidence has also shown that abnormal BMI can predict prognosis in many types of cancers [14-23], such as breast [14], colon [15] and liver [22] cancers, and diffuse large B-cell lymphoma (DLBCL) [17-19]. Although there is sufficient evidence in these cancers, the role of BMI in ENKTL is still unclear. Therefore, we carried out this retrospective study to determine the 
prognostic value of BMI in newly diagnosed patients with ENKTL.

\section{RESULTS}

\section{Patient characteristics}

In total, 301 patients met the inclusion criteria. Fifty cases were excluded. Of these, 28 patients had primary extranasal diseases, 9 were younger than 18 years, 6 were complicated by other types of cancer, and the staging was unclear in 7 patients. The median age of the remaining 251 eligible patients was 42 years (range, 18-86 years), and $170(67.7 \%)$ patients were male. At diagnosis, 40 patients $(15.9 \%)$ were classified as underweight, 130 $(51.8 \%)$ as normal weight, $49(19.6 \%)$ as overweight, and $32(12.7 \%)$ as obese according to the Asian criteria of BMI classification. Most $(n=203,80.9 \%)$ patients received chemoradiotherapy, $37(14.7 \%)$ received chemotherapy alone, $8(3.2 \%)$ received radiotherapy alone, and $3(1.2 \%)$ received only best supportive care. The chemotherapy regimens included VDLP (etoposide, dexamethasone, L-asparaginase, and cisplatin: 184 patients), LVP (L-asparaginase, vincristine, and prednisone: 36 patients), asparaginase combined with non-anthracycline drugs (e.g., gemcitabine, irinotecan, or dexamethasone: 8 patients), CHOP (doxorubicin, cyclophosphamide, vincristine, and prednisone: 8 patients), and other regimens in 4 patients. Of patients treated with radiotherapy, 205 (97.2\%) completed the planned dose (50-56 Gy). By December 2015, 79 patients had died. The median follow-up time was 28 months (range, 8-86 months) for patients who were alive. The estimated 3-year OS and PFS rates were $64.4 \%$ and $60.9 \%$, respectively. Patient characteristics are listed in Table 1.
A

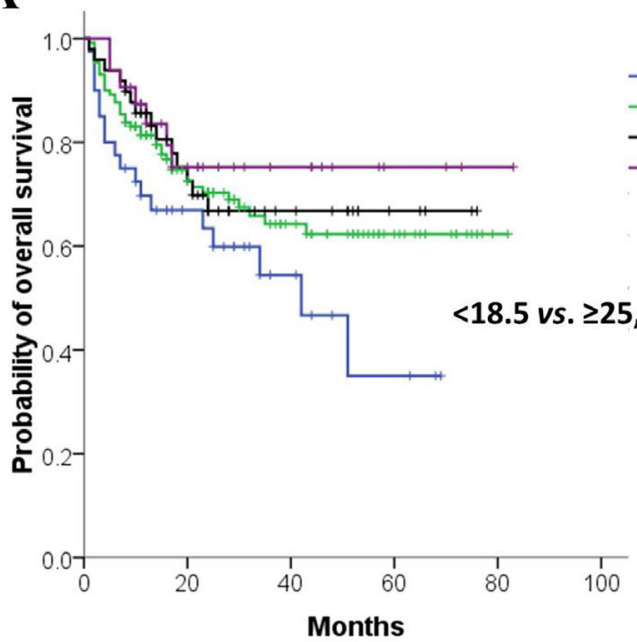

C

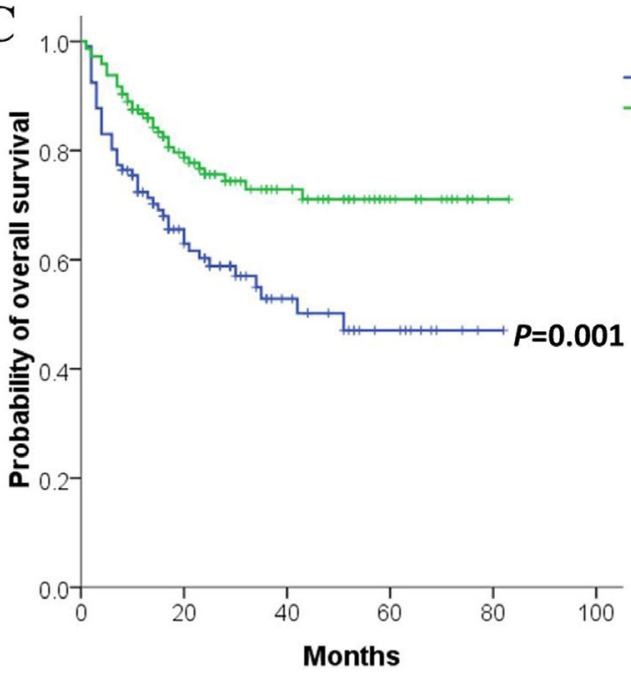

B

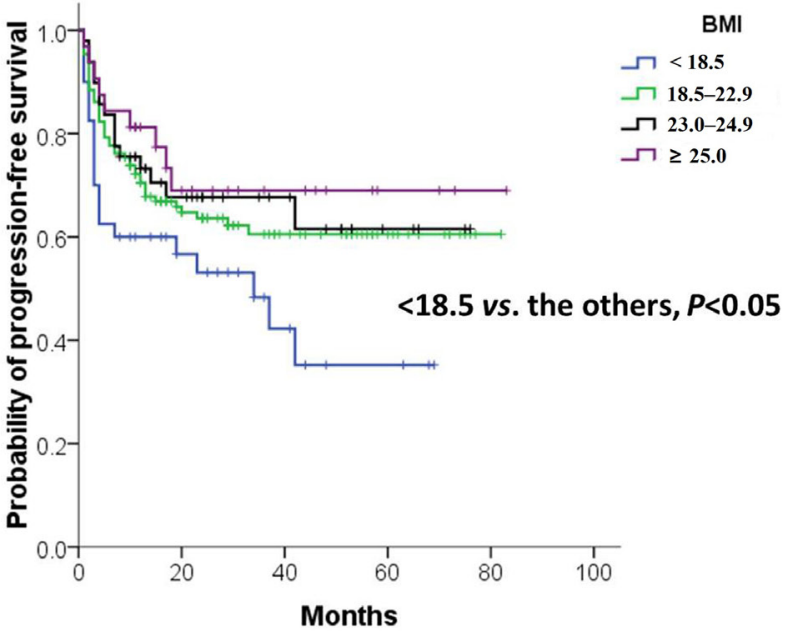

sin D

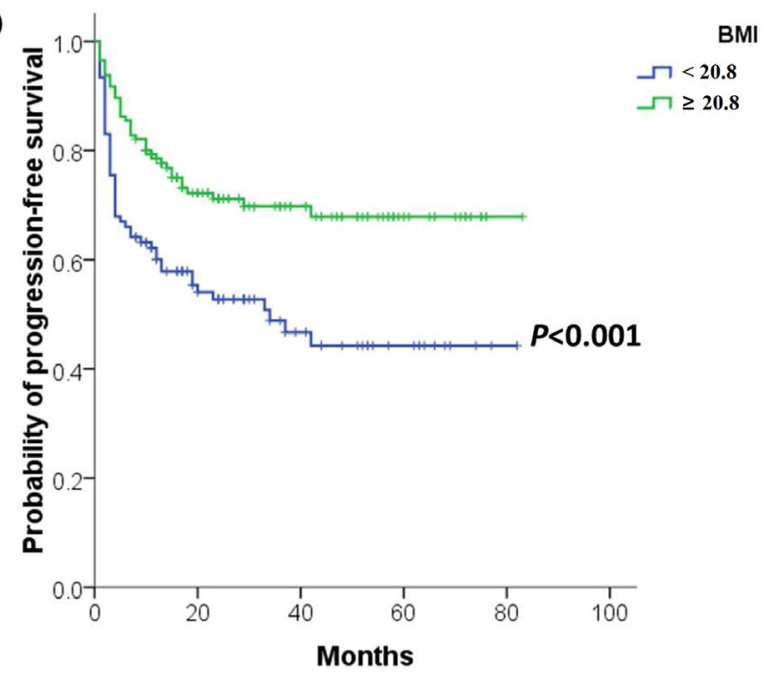

Figure 1: Survival curves of 251 patients diagnosed with ENKTL. A. and B. Patients were stratified into BMI groups according to the Asian criteria: underweight $\left(<18.5 \mathrm{~kg} / \mathrm{m}^{2}\right)$, normal weight $\left(18.5-22.9 \mathrm{~kg} / \mathrm{m}^{2}\right)$, overweight $\left(23.0-24.9 \mathrm{~kg} / \mathrm{m}^{2}\right)$ and obese $(\geq 25.0 \mathrm{~kg} /$ $\left.\mathrm{m}^{2}\right)$. C. and D. Patients were divided by the optimal cut-off of BMI $\left(20.8 \mathrm{~kg} / \mathrm{m}^{2}\right)$. 
Table 1: Patient characteristics

\begin{tabular}{|c|c|c|c|c|c|}
\hline Characteristic & No. of patients & $\%$ & Characteristic & No. of patients & $\%$ \\
\hline Gender & & & Ann Arbor Stage & & \\
\hline Female & 81 & $32.3 \%$ & I-II & 213 & $84.9 \%$ \\
\hline Male & 170 & $67.7 \%$ & III-IV & 38 & $15.1 \%$ \\
\hline Age & & & Local invasiveness & & \\
\hline$\leq 60$ & 219 & $87.3 \%$ & No & 178 & $70.9 \%$ \\
\hline$>60$ & 32 & $12.7 \%$ & Yes & 73 & $29.1 \%$ \\
\hline B symptoms & & & RLN involvement & & \\
\hline No & 122 & $48.6 \%$ & No & 164 & $65.3 \%$ \\
\hline Yes & 129 & $51.4 \%$ & Yes & 87 & $34.7 \%$ \\
\hline Performance status & & & DLN involvement & & \\
\hline $0-1$ & 223 & $88.8 \%$ & No & 236 & $94.0 \%$ \\
\hline $2-4$ & 28 & $11.2 \%$ & Yes & 15 & $6.0 \%$ \\
\hline LDH & & & No. of extranodal sites & & \\
\hline Normal & 151 & $60.2 \%$ & 1 site & 216 & $86.1 \%$ \\
\hline Elevated & 100 & $39.8 \%$ & $>1$ site & 35 & $13.9 \%$ \\
\hline BMI & & & Radiotherapy & & \\
\hline$<18.5$ & 40 & $15.9 \%$ & No & 40 & $15.9 \%$ \\
\hline $18.5-22.9$ & 130 & $51.8 \%$ & Yes & 211 & $84.1 \%$ \\
\hline $23-24.9$ & 49 & $19.6 \%$ & Chemotherapy & & \\
\hline$\geq 25$ & 32 & $12.7 \%$ & With asparaginase & 228 & $90.8 \%$ \\
\hline & & & Without asparaginase & 12 & $4.8 \%$ \\
\hline & & & No & 11 & $4.4 \%$ \\
\hline
\end{tabular}

\section{The prognostic value of $\mathrm{BMI}$ in patients with ENKTL}

It was found that the estimated 3-year OS rates were $54.5 \%, 64.3 \%, 66.8 \%$, and $75.2 \%$, and the 3 -year PFS rates were $48.3 \%, 60.5 \%, 66.8 \%$, and $69.0 \%$ for underweight, normal weight, overweight, and obese patients, respectively. Survival curves showed that the significant difference of OS was only between underweight and obese patients $(P=0.045$, Figure 1A). The PFS of the underweight group was shorter than that of other groups (all $P<0.05$ ), and similar PFS curves were observed in normal weight, overweight and obese patients (Figure 1B). Therefore, patients were dichotomized into the following groups: $\mathrm{BMI}<18.5 \mathrm{~kg} / \mathrm{m}^{2}$ and $\mathrm{BMI} \geq 18.5$ $\mathrm{kg} / \mathrm{m}^{2}$. Patients with BMI $<18.5 \mathrm{~kg} / \mathrm{m}^{2}$ had inferior 3-year OS (54.5\% vs. $66.3 \%, P=0.035)$ and PFS $(48.3 \%$ vs. $63.4 \%, P=0.017)$ rates than those with BMI $\geq 18.5 \mathrm{~kg} /$ $\mathrm{m}^{2}$. However, BMI at the cut-off of $18.5 \mathrm{~kg} / \mathrm{m}^{2}$ was not an independent prognostic factor for either OS [(hazard ratio $(H R)=1.555,95 \%$ confidence interval $(C I)=0.903-2.681$, $P=0.111)]$ or PFS $(H R=1.600,95 \% C I=0.955-2.681$, $P=0.074)$.

The receiver operating characteristic (ROC) curve analysis indicated that $20.8 \mathrm{~kg} / \mathrm{m}^{2}$ was the optimal cut-off value of BMI to predict survival (area under the curve $=$ $0.592, P=0.020$ ). Patients with BMI $<20.8 \mathrm{~kg} / \mathrm{m}^{2}$ had lower 3-year OS (52.8\% vs. 72.9\%, $P=0.001$, Figure 1C) and PFS (48.8\% vs. $69.8 \%, P<0.001$, Figure 1D) rates than patients with $\mathrm{BMI} \geq 20.8 \mathrm{~kg} / \mathrm{m}^{2}$. Multivariate analysis indicated that BMI at this cut-off was an independent prognostic factor for both OS and PFS (Table 2). Patients were further stratified to perform subgroup analyses to identify those who might be compromised by a low BMI $\left(\mathrm{BMI}<20.8 \mathrm{~kg} / \mathrm{m}^{2}\right.$ ) according to the stage (early stage $v s$. advanced stage), use of radiotherapy (yes $v s$. no), and the regimen of chemotherapy (asparaginase-containing $v s$. non-asparaginase-containing). It was found that in patients with early stage $(n=213)$, receiving radiotherapy 
Table 2: Multivariate analysis in 251 patients with ENKTL

\begin{tabular}{|c|c|c|c|c|}
\hline \multirow[b]{2}{*}{ Characteristic } & \multicolumn{2}{|l|}{ Overall survival } & \multicolumn{2}{|c|}{ Progression-free survival } \\
\hline & $H R(95 \% C I)$ & $P$ value & $H R(95 \% C I)$ & $P$ value \\
\hline Gender (male $v s$. female) & $1.708(0.997-2.927)$ & 0.051 & $1.338(0.821-2.182)$ & 0.243 \\
\hline Ann Arbor Stage (III-IV vs. I-II) & $0.000\left(0.000-6.493 \times 10^{48}\right)$ & 0.887 & $3.114(0.772-12.565)$ & 0.111 \\
\hline Local invasiveness (yes $v s$. no) & $1.367(0.790-2.366)$ & 0.264 & $1.251(0.761-2.057)$ & 0.377 \\
\hline RLN involvement (yes vs. no) & $1.491(0.886-2.510)$ & 0.132 & $1.514(0.937-2.444)$ & 0.090 \\
\hline DLN involvement (yes $v s$. no) & $0.970(0.375-2.505)$ & 0.949 & $1.130(0.457-2.792)$ & 0.791 \\
\hline No. of extranodal sites (>1 vs. 1 ) & $4534.994\left(0.000-1.913 \times 10^{56}\right)$ & 0.892 & $6.623(1.667-26.316)$ & 0.007 \\
\hline B symptoms (yes vs. no) & $0.832(0.486-1.426)$ & 0.504 & $0.841(0.508-1.393)$ & 0.501 \\
\hline Performance status (2-4 vs. $0-1)$ & $4.172(2.086-8.346)$ & $<0.001$ & $2.723(1.385-5.354)$ & 0.004 \\
\hline LDH (elevated $v s$. normal) & $2.349(1.390-3.970)$ & 0.001 & $1.725(1.063-2.797)$ & 0.027 \\
\hline Chemotherapy (per 1-degree increase) ${ }^{a}$ & $0.612(0.407-0.922)$ & 0.019 & $0.717(0.490-1.048)$ & 0.086 \\
\hline Radiotherapy (yes vs. no) & $0.283(0.149-0.538)$ & $<0.001$ & $0.156(0.077-0.316)$ & $<0.001$ \\
\hline BMI $(<20.8 v s . \geq 20.8)$ & $1.689(1.049-2.717)$ & 0.031 & $1.656(1.059-2.591)$ & 0.027 \\
\hline
\end{tabular}

Note: ${ }^{\text {a }}$ Patients treated without chemotherapy, with non-asparaginase-based chemotherapy, and with asparaginase-containing chemotherapy were assigned the values 1,2 , and 3 , respectively.

$(n=211)$, and undergoing asparaginase-containing chemotherapy $(n=228)$, BMI $<20.8 \mathrm{~kg} / \mathrm{m}^{2}$ was associated with poor survival outcomes (all $P<0.050$ ).

\section{Association between BMI and other characteristics}

A greater proportion of patients with $\mathrm{BMI}<20.8 \mathrm{~kg} /$ $\mathrm{m}^{2}$ were female $(39.6 \%$ vs. $26.9 \%, P=0.033)$, presented with advanced stage disease $(21.7 \% v s .10 .3 \%, P=0.013)$, RLN involvement $(42.5 \%$ vs. $29.0 \%, P=0.027)$, DLN involvement $(11.3 \%$ vs. $2.1 \%, P=0.002)$, and extranodal sites $>1(19.8 \%$ vs. 9.7\%, $P=0.022)$, and were treated without radiotherapy in first-line treatment $(24.5 \% v s$. $9.7 \%, P=0.001$ ) than those with BMI $\geq 20.8 \mathrm{~kg} / \mathrm{m}^{2}$ (Table 3). In patients receiving antitumor treatment, patients with BMI $<20.8 \mathrm{~kg} / \mathrm{m}^{2}$ were more likely to receive radiotherapy doses of less than 50 Gy $(6.3 \%$ vs. $0.8 \%, P$ $=0.030)$ and chemotherapy of less than 3 cycles $(32.0 \%$ vs. $16.4 \%, P=0.005$ ) than those with BMI $\geq 20.8 \mathrm{~kg} / \mathrm{m}^{2}$ (Table 3).

\section{Treatment-related adverse events based on BMI}

Among 248 patients receiving antitumor treatment, grade 3-4 hematological and hepatic toxicities occurred in $86(34.7 \%)$ and $12(4.8 \%)$ patients, respectively. There was no grade 3-4 nephritic toxicity. Treatment-related mortality rate was $2.4 \%$. Grade $3-4$ neutropenia $(33.3 \%$ vs. $19.6 \%, P=0.014)$ and treatment interruption $(9.5 \%$ vs. $2.1 \%, P=0.010$ ) were more likely to occur in patients with BMI $<20.8 \mathrm{~kg} / \mathrm{m}^{2}$ than in those with BMI $\geq 20.8 \mathrm{~kg} /$ $\mathrm{m}^{2}$ (Table 4).

\section{DISCUSSION}

In this study, we found that BMI at diagnosis was an independent prognostic factor in newly diagnosed ENKTL patients, after being adjusted for other theoretical confounding factors. To the best of our knowledge, our study represents the first large cohort to evaluate the prognostic value of BMI in patients with ENKTL.

The survival rates of ENKTL patients seemed greater with higher BMI, but a statistically significant difference did not exist between normal weight and overweight/obese patients (Figure 1A and 1B). In fact, the prognostic value of overweight/obese status in cancer remains controversial. Obesity, rather than overweight, was associated with higher mortality in breast and colorectal cancers [14, 24], but being overweight or obese improved clinical outcomes of liver, and head and neck cancers $[16,22]$. In DLBCL, overweight/obesity was a favorable prognostic factor in two studies conducted in America and Austria [17, 18], but the OS did not seem different among normal weight, overweight, and obese patients in another study by a Korean group [19], which seemed consistent with our findings in ENKTL (Figure 1A).

As similar prognosis were observed in normal weight and overweight/obese patients (Figure 1A and 1B), 
Table 3: Association between BMI and other characteristics

\begin{tabular}{|c|c|c|c|}
\hline Characteristic & BMI $<20.8$ & BMI $\geq 20.8$ & $P$ value \\
\hline Gender & & & 0.033 \\
\hline Female & 42 & 39 & \\
\hline Male & 64 & 106 & \\
\hline Age & & & 0.844 \\
\hline$\leq 60$ & 93 & 126 & \\
\hline$>60$ & 13 & 19 & \\
\hline Ann Arbor & & & 0.013 \\
\hline I-II & 83 & 130 & \\
\hline III-IV & 23 & 15 & \\
\hline Local invasiveness & & & 0.742 \\
\hline No & 74 & 104 & \\
\hline Yes & 32 & 41 & \\
\hline RLN involvement & & & 0.027 \\
\hline No & 61 & 103 & \\
\hline Yes & 45 & 42 & \\
\hline DLN involvement & & & 0.002 \\
\hline No & 94 & 142 & \\
\hline Yes & 12 & 3 & \\
\hline Extranodal involvement & & & 0.022 \\
\hline 1 site & 85 & 131 & \\
\hline$>1$ site & 21 & 14 & \\
\hline B symptoms & & & 0.519 \\
\hline No & 49 & 73 & \\
\hline Yes & 57 & 72 & \\
\hline Performance status & & & 0.090 \\
\hline $0-1$ & 90 & 133 & \\
\hline $2-4$ & 16 & 12 & \\
\hline $\mathrm{LDH}$ & & & 0.077 \\
\hline Normal & 57 & 94 & \\
\hline Elevated & 49 & 51 & \\
\hline Chemotherapy & & & $0.535^{\mathrm{a}}$ \\
\hline No & 6 & 5 & \\
\hline Yes & 100 & 140 & \\
\hline Chemotherapy cycles & & & 0.005 \\
\hline$<3$ & 32 & 23 & \\
\hline$\geq 3$ & 68 & 117 & \\
\hline Radiotherapy & & & 0.001 \\
\hline No & 26 & 14 & \\
\hline Yes & 80 & 131 & \\
\hline Radiotherapy dosage & & & $0.030 \mathrm{a}$ \\
\hline$<50 \mathrm{~Gy}$ & 5 & 1 & \\
\hline$\geq 50 \mathrm{~Gy}$ & 75 & 130 & \\
\hline
\end{tabular}

Note: ${ }^{\text {a }}$ Fisher's exact test. 
Table 4: Treatment-related adverse events based on BMI

\begin{tabular}{|c|c|c|c|}
\hline Adverse event & BMI $<20.8$ & $\mathrm{BMI} \geq 20.8$ & $P$ value \\
\hline Anemia & & & 0.095 \\
\hline Grade $0-2$ & 93 & 135 & \\
\hline Grade 3-4 & 12 & 8 & \\
\hline Leukopenia & & & 0.055 \\
\hline Grade $0-2$ & 70 & 111 & \\
\hline Grade 3-4 & 35 & 32 & \\
\hline Neutropenia & & & 0.014 \\
\hline Grade $0-2$ & 70 & 115 & \\
\hline Grade 3-4 & 35 & 28 & \\
\hline Thrombopenia & & & 0.154 \\
\hline Grade $0-2$ & 95 & 136 & \\
\hline Grade 3-4 & 10 & 7 & \\
\hline Elevated transaminase & & & $0.289^{\mathrm{a}}$ \\
\hline Grade $0-2$ & 100 & 140 & \\
\hline Grade 3-4 & 5 & 3 & \\
\hline Elevated bilirubin & & & $0.999^{\mathrm{a}}$ \\
\hline Grade $0-2$ & 101 & 138 & \\
\hline Grade 3-4 & 4 & 5 & \\
\hline Elevated creatinine & & & $0.999^{\mathrm{a}}$ \\
\hline Grade 0 & 103 & 139 & \\
\hline Grade 1-2 & 2 & 4 & \\
\hline Treatment interruption & & & 0.010 \\
\hline No & 95 & 140 & \\
\hline Yes & 10 & 3 & \\
\hline Treatment-related death & & & $0.245^{\mathrm{a}}$ \\
\hline No & 101 & 141 & \\
\hline Yes & 4 & 2 & \\
\hline
\end{tabular}

Note: ${ }^{\text {a }}$ Fisher's exact test.

we adopted a dichotomized classification of BMI with a cut-off of $18.5 \mathrm{~kg} / \mathrm{m}^{2}$. The survival of patients with BMI $<18.5 \mathrm{~kg} / \mathrm{m}^{2}$ was poorer than that of patients with BMI $\geq 18.5 \mathrm{~kg} / \mathrm{m}^{2}$ in ENKTL. It was consistent with previous findings in breast, colon, and head and neck cancers [14, $15,20,23]$. However, multivariate analysis suggested that BMI at the cut-off of $18.5 \mathrm{~kg} / \mathrm{m}^{2}$ was not an independent prognostic factor in ENKTL. Therefore, an ROC curve analysis was conducted, which suggested that $20.8 \mathrm{~kg} /$ $\mathrm{m}^{2}$ was the optimal cut-off value. BMI $<20.8 \mathrm{~kg} / \mathrm{m}^{2}$ was associated with lower 3-year OS (Figure 1C) and PFS (Figure 1D) rates. Multivariate analysis also indicated that $\mathrm{BMI}$ at this cut-off was an independent prognostic factor (Table 2).

A series of studies support that patients with ENKTL can benefit from asparaginase-containing chemotherapy [7-10, 25]. Early or upfront radiotherapy is also an effective treatment to improve clinical outcome of localized disease [2, 4-6]. We confirmed these findings in the present study (Table 2). Moreover, based on the results of multivariate analysis and subgroup analysis, our findings further suggested that BMI could predict the clinical outcome of ENKTL patients who received the current mainstream treatment strategies.

The reason for poor prognosis among low-weight cancer patients is not well known. One explanation is that underweight patients may be more likely to suffer from comorbidities that increase mortality risk, such as higher rate of second malignancies [15]. In our study, 6 patients who were complicated by other types of cancer were excluded. Therefore, it might not be the reason in ENKTL. Another explanation is that low-weight patients might experience chronic undernutrition, which could weaken the immune system $[14,26]$. In our study, BMI $<20.8 \mathrm{~kg} /$ $\mathrm{m}^{2}$ was associated with other adverse prognostic factors and the absence of early radiotherapy (Table 3 ). Moreover, 
patients with lower BMI were more likely to receive less radiotherapy doses and chemotherapy cycles in first-line treatment (Table 3) and experience severe neutropenia and adverse event-related treatment interruption (Table 4). These associations might be the reason for poor prognosis among low-weight patients with ENKTL.

There are several potential limitations in this singleinstitution retrospective study. Firstly, we excluded patients with primarily extranasal disease. Secondly, most patients (184 of 251) were treated with the chemotherapy regimen of VDLP. These factors limit the ability to extrapolate our findings to the entire ENKTL patient population, especially considering that a standardized chemotherapy regimen for ENKTL is not well established. Thirdly, BMI has limitations in evaluating the patients with sarcopenic or non-sarcopenic obesity [27]. Sarcopenia and visceral obesity were associated with poor survival in some malignant tumors [28-30]. Finally, we could not rule out the possibility of other confounding factors, such as socioeconomic status that might influence the BMI of patients.

In summary, our results indicated that BMI was a prognostic factor for patients with ENKTL in the context of current treatment strategy. Prospective multicentric studies are needed to further confirm this finding in the entire ENKTL patient population.

\section{MATERIALS AND METHODS}

\section{Patient population and data collection}

The study was approved by the Ethics Committee of West China Hospital of Sichuan University. We retrospectively analyzed the data of patients diagnosed with ENKTL between July 2008 and April 2015 in our center. Patients were included if: (1) they were newly diagnosed with ENKTL, and (2) their BMI data were available. Patients were excluded if: (1) their diseases primarily occurred in extranasal sites, (2) they were younger than 18 years, (3) they were athletes, (4) they were pregnant or lactating women, (5) they had other types of cancer, and (6) their staging was unclear. Patient characteristics including age, sex, weight, height, Ann Arbor stage, local invasiveness [31], RLN involvement [3], DLN involvement [11], number of extranodal sites, B symptoms, Eastern Cooperative Oncology Group performance status, serum LDH level, first-line treatment regimens, and survival status were recorded. BMI was calculated as weight in kilograms divided by height in meters squared $\left(\mathrm{kg} / \mathrm{m}^{2}\right)$. Patients were stratified into BMI groups according to the Asian criteria: underweight ( $<$ $\left.18.5 \mathrm{~kg} / \mathrm{m}^{2}\right)$, normal weight $\left(18.5-22.9 \mathrm{~kg} / \mathrm{m}^{2}\right)$, overweight $\left(23.0-24.9 \mathrm{~kg} / \mathrm{m}^{2}\right)$ and obese $\left(\geq 25.0 \mathrm{~kg} / \mathrm{m}^{2}\right)$ [19]. Progression-free survival was defined as the time interval from diagnosis to disease progression, relapse or death as a result of any cause. Overall survival was defined as the time from diagnosis to death as a result of any cause.

\section{Statistical analysis}

Categorical variables were summarized as frequency counts and were analyzed using the Chi-squared test. If appropriate, Fisher's exact test was performed. The optimal cut-off value of BMI to predict prognosis was calculated using an ROC curve analysis referring to death of patients. Both OS and PFS were estimated using the Kaplan-Meier method, and survival curves were compared using the log-rank test. Only those factors that were statistically associated with survival at the 0.1 level $(P \leq 0.100)$ in the log-rank test were included in the multivariate analysis of Cox proportional hazard model. All statistical tests were performed using SPSS v17.0 (SPSS, Inc., Chicago, IL), and two-sided $P \leq 0.05$ was considered statistically significant.

\section{ACKNOWLEDGMENTS}

The authors would like to thank Dr. Bo-Yan Huang and Di Luo for providing language guidance.

\section{CONFLICTS OF INTEREST}

We declare that no conflict of interest exists in this manuscript.

\section{FUNDING}

This study was supported by the National Natural Science Foundation of China (81572853).

\section{REFERENCES}

1. Gill H, Liang RH, Tse E. Extranodal natural-killer/t-cell lymphoma, nasal type. Adv Hematol 2010; 2010: 627401.

2. Au WY, Weisenburger DD, Intragumtornchai T, Nakamura S, Kim WS, Sng I, Vose J, Armitage JO, Liang R; International Peripheral T-Cell Lymphoma Project. Clinical differences between nasal and extranasal natural killer/Tcell lymphoma: a study of 136 cases from the International Peripheral T-Cell Lymphoma Project. Blood 2009; 113: 3931-3937.

3. Lee J, Suh C, Park YH, Ko YH, Bang SM, Lee JH, Lee DH, Huh J, Oh SY, Kwon HC, Kim HJ, Lee SI, Kim JH, et al. Extranodal natural killer T-cell lymphoma, nasal-type: a prognostic model from a retrospective multicenter study. $\mathrm{J}$ Clin Oncol 2006; 24: 612-618.

4. You JY, Chi KH, Yang MH, Chen CC, Ho CH, Chau WK, Hsu HC, Gau JP, Tzeng CH, Liu JH, Chen PM, Chiou TJ. 
Radiation therapy versus chemotherapy as initial treatment for localized nasal natural killer (NK)/T-cell lymphoma: a single institute survey in Taiwan. Ann Oncol 2004; 15: 618625 .

5. Huang MJ, Jiang Y, Liu WP, Li ZP, Li M, Zhou L, Xu Y, Yu CH, Li Q, Peng F, Liu JY, Luo F, Lu Y. Early or up-front radiotherapy improved survival of localized extranodal NK/T-cell lymphoma, nasal-type in the upper aerodigestive tract. Int J Radiat Oncol Biol Phys 2008; 70: 166-174.

6. Li YX, Yao B, Jin J, Wang WH, Liu YP, Song YW, Wang SL, Liu XF, Zhou LQ, He XH, Lu N, Yu ZH. Radiotherapy as primary treatment for stage IE and IIE nasal natural killer/T-cell lymphoma. J Clin Oncol 2006; 24: 181-189.

7. Jiang M, Zhang H, Jiang Y, Yang Q, Xie L, Liu W, Zhang W, Ji X, Li P, Chen N, Zhao S, Wang F, Zou L. Phase 2 trial of "sandwich" L-asparaginase, vincristine, and prednisone chemotherapy with radiotherapy in newly diagnosed, stage IE to IIE, nasal type, extranodal natural killer/T-cell lymphoma. Cancer 2012; 118: 3294-3301.

8. Jaccard A, Gachard N, Marin B, Rogez S, Audrain M, Suarez F, Tilly H, Morschhauser F, Thieblemont C, Ysebaert L, Devidas A, Petit B, de Leval L, et al. Efficacy of L-asparaginase with methotrexate and dexamethasone (AspaMetDex regimen) in patients with refractory or relapsing extranodal NK/T-cell lymphoma, a phase 2 study. Blood 2011; 117: 1834-1839.

9. Wang L, Wang ZH, Chen XQ, Li YJ, Wang KF, Xia YF, Xia ZJ. First-line combination of gemcitabine, oxaliplatin, and L-asparaginase (GELOX) followed by involved-field radiation therapy for patients with stage IE/IIE extranodal natural killer/T-cell lymphoma. Cancer 2013; 119: 348-355.

10. Yamaguchi M, Kwong YL, Kim WS, Maeda Y, Hashimoto C, Suh C, Izutsu K, Ishida F, Isobe Y, Sueoka E, Suzumiya J, Kodama T, Kimura H, et al. Phase II study of SMILE chemotherapy for newly diagnosed stage IV, relapsed, or refractory extranodal natural killer (NK)/T-cell lymphoma, nasal type: the NK-Cell Tumor Study Group study. J Clin Oncol 2011; 29: 4410-4416.

11. Kim SJ, Yoon DH, Jaccard A, Chng WJ, Lim ST, Hong H, Park Y, Chang KM, Maeda Y, Ishida F, Shin DY, Kim JS, Jeong SH, et al. A prognostic index for natural killer cell lymphoma after non-anthracycline-based treatment: a multicentre, retrospective analysis. Lancet Oncol 2016; 17: 389-400.

12. WHO Expert Consultation. Appropriate body-mass index for Asian populations and its implications for policy and intervention strategies. Lancet 2004; 363: 157-163.

13. Reeves GK, Pirie K, Beral V, Green J, Spencer E, Bull D; Million Women Study Collaboration. Cancer incidence and mortality in relation to body mass index in the Million Women Study: cohort study. BMJ 2007; 335: 1134.

14. Kawai M, Tomotaki A, Miyata H, Iwamoto T, Niikura N, Anan K, Hayashi N, Aogi K, Ishida T, Masuoka H, Iijima $\mathrm{K}$, Masuda S, Tsugawa $\mathrm{K}$, et al. Body mass index and survival after diagnosis of invasive breast cancer: a study based on the Japanese National Clinical Database-Breast Cancer Registry. Cancer Med 2016; 5:1328-1340.

15. Dignam JJ, Polite BN, Yothers G, Raich P, Colangelo L, O'Connell MJ, Wolmark N. Body mass index and outcomes in patients who receive adjuvant chemotherapy for colon cancer. J Natl Cancer Inst 2006; 98: 1647-1654.

16. McRackan TR, Watkins JM, Herrin AE, Garrett-Mayer EM, Sharma AK, Day TA, Gillespie MB. Effect of body mass index on chemoradiation outcomes in head and neck cancer. Laryngoscope 2008; 118: 1180-1185.

17. Weiss L, Melchardt T, Habringer S, Boekstegers A, Hufnagl C, Neureiter D, Hopfinger G, Greil R, Egle A. Increased body mass index is associated with improved overall survival in diffuse large B-cell lymphoma. Ann Oncol 2014; 25: 171-176.

18. Carson KR, Bartlett NL, McDonald JR, Luo S, Zeringue A, Liu J, Fu Q, Chang SH, Colditz GA. Increased body mass index is associated with improved survival in United States veterans with diffuse large B-cell lymphoma. J Clin Oncol 2012; 30: 3217-3222.

19. Hwang HS, Yoon DH, Suh C, Huh J. Body mass index as a prognostic factor in Asian patients treated with chemoimmunotherapy for diffuse large B cell lymphoma, not otherwise specified. Ann Hematol 2015; 94: 1655-1665.

20. Takenaka Y, Takemoto N, Nakahara S, Yamamoto Y, Yasui T, Hanamoto A, Fukusumi T, Michiba T, Cho H, Yamamoto M, Inohara H. Prognostic significance of body mass index before treatment for head and neck cancer. Head Neck 2015; 37: 1518-1523.

21. Xu X, Zhou L, Miao R, Chen W, Zhou Y, Pang Q, Qu K, Liu C. Association of cancer mortality with postdiagnosis overweight and obesity using body mass index. Oncotarget 2016; 7: 5023-5029. doi:10.18632/oncotarget.6517.

22. Lee YL, Li WC, Tsai TH, Chiang HY, Ting CT. Body mass index and cholesterol level predict surgical outcome in patients with hepatocellular carcinoma in taiwan - a cohort study. Oncotarget 2016; 7:22948-22959. doi:10.18632/ oncotarget.8312.

23. Zeng Q, Hong MH, Shen LJ, Meng XQ, Guo X, Qian CN, $\mathrm{Wu} \mathrm{PH}$, Huang PY. Nomograms for predicting long-term survival in patients with non-metastatic nasopharyngeal carcinoma in an endemic area. Oncotarget 2016; doi: 10.18632/oncotarget.8823.

24. Doleman B, Mills KT, Lim S, Zelhart MD, Gagliardi G. Body mass index and colorectal cancer prognosis: a systematic review and meta-analysis. Tech Coloproctol 2016; 20:517-535.

25. Wang L, Wang WD, Xia ZJ, Zhang YJ, Xiang J, Lu Y. Combination of gemcitabine, L-asparaginase, and oxaliplatin (GELOX) is superior to EPOCH or CHOP in the treatment of patients with stage IE/IIE extranodal natural killer/T cell lymphoma: a retrospective study in a cohort of 227 patients with long-term follow-up. Med Oncol 2014; 
31: 860 .

26. Cunningham-Rundles S, McNeeley DF, Moon A. Mechanisms of nutrient modulation of the immune response. J Allergy Clin Immunol 2005; 115: 1119-1128; quiz 1129.

27. Tan BH, Birdsell LA, Martin L, Baracos VE, Fearon KC. Sarcopenia in an overweight or obese patient is an adverse prognostic factor in pancreatic cancer. Clin Cancer Res 2009; 15: 6973-6979.

28. Shachar SS, Williams GR, Muss HB, Nishijima TF. Prognostic value of sarcopenia in adults with solid tumours: A meta-analysis and systematic review. Eur J Cancer 2016; 57: 58-67.

29. Go SI, Park MJ, Song HN, Kim HG, Kang MH, Lee HR, Kim Y, Kim RB, Lee SI, Lee GW. Prognostic impact of sarcopenia in patients with diffuse large B-cell lymphoma treated with rituximab plus cyclophosphamide, doxorubicin, vincristine, and prednisone. J Cachexia Sarcopenia Muscle 2016. [Epub ahead of print]
30. Shin DY, Kim A, Byun BH, Moon H, Kim S, Ko YJ, Kim MJ, Lee HR, Kang HJ, Na, II, Park S, Lee SS, Yang SH. Visceral adipose tissue is prognostic for survival of diffuse large B cell lymphoma treated with frontline R-CHOP. Ann Hematol 2016; 95: 409-416.

31. Kim TM, Park YH, Lee SY, Kim JH, Kim DW, Im SA, Kim TY, Kim CW, Heo DS, Bang YJ, Chang KH, Kim NK. Local tumor invasiveness is more predictive of survival than International Prognostic Index in stage I(E)/II(E) extranodal NK/T-cell lymphoma, nasal type. Blood 2005; 106: 3785-3790. 